\title{
RE: Parenchymal biopsy in the management of patients with renal cancer
}

\author{
Gaetano Ciancio' ${ }^{1}$ (1)
}

Received: 25 January 2021 / Accepted: 30 January 2021 / Published online: 24 March 2021

(c) The Author(s), under exclusive licence to Springer-Verlag GmbH Germany, part of Springer Nature 2021

\section{Dear Editor,}

I read the article by Capitanio et al. [1] studied the renal parenchyma of non-tumor tissue after radical nephrectomy in patients with renal cell carcinoma (RCC). In their conclusion, renal parenchymal damage (RPD) in non-tumor tissue was an independent predictor of functional impairment in patients with RCC.

We studied non-neoplastic pathologic changes in specimens of patients with RCC that underwent partial nephrectomy. A total of 45 patients were studied that had no previous history of renal disease or comorbidities. Those patients had already RPD and the most common finding was atherosclerosis (20\%) followed by mesangial expansion and interstitial fibrosis in $17.8 \%$ of patients. Clinical recommendations were made to proceed with medical intervention to preserve the remaining renal function [2]. Then we studied non-neoplastic specimens in a cohort of 114 patients that underwent renal surgery for RCC. Hypertension, diabetes and coronary artery disease were seen in 54.5, 16.7 and $12.3 \%$ of the patients, respectively. Significant non-neoplastic parenchyma moderate to severe atherosclerosis was observed in $25.4 \%(n=29)$ of the patients. Only $17(58.6 \%)$ had a statin drug being prescribed at the time of surgery.

We recommended lifestyle modification and medical therapy (weight loss, smoking cessation) to avoid renal replacement in those patients with a previous history of comorbidities and RCC [3]. I agree with Capitanio et al. [1] that we should analyze the non-neoplastic renal parenchyma with the goal of helping the patient with RCC to preserve

This comment refers to the article available online at https://doi. org/10.1007/s00345-020-03572-7.

Gaetano Ciancio

gciancio@med.miami.edu

1 Department of Surgery and Urology, Miami Transplant Institute, University of Miami Miller School of Medicine, Jackson Memorial Hospital, Miami, FL, USA renal function and avoid renal replacement. Initiation and/ or modification of medical therapy could have an impact in improving patient survival.

Author contributions GC: Manuscript and editing.

\section{Compliance with ethical standards}

Conflict of interest The author certifies that he has no affiliations with or involvement in any organization or entity with any financial interest or non-financial interest in the subject matter or materials discussed in this manuscript.

Ethical approval This is a letter to editors and does not involve any animal or human subjects to obtain consent.

\section{References}

1. Capitanio U, Larcher A, Fallara G, Trevisani F, Porrini E, Di Marco F, Baiamonte G, Re C, Bettiga A, Dell'Antonio G, Doglioni C, De Cobelli F, Bertini R, Salonia A, Montorsi F (2021) Parenchymal biopsy in the management of patients with renal cancer. World J Urol. https://doi.org/10.1007/s00345-020-03572-7

2. Garcia-Roig M, Gorin MA, Parra-Herran C, Garcia-Buitrago M, Kava BR, Jorda M, Soloway MS, Manoharan M, Ciancio G (2013) Pathologic evaluation of non-neoplastic renal parenchyma in partial nephrectomy specimens. World J Urol 31:835-839

3. Gorin MA, Garcia-Roig M, Garcia-Buitrago M, Parra-Herran C, Jorda M, Ciancio G (2013) Atherosclerosis within the nonneoplastic margin of partial nephrectomy specimens: implications for medical management. World J Urol 31:1531-1534

Publisher's Note Springer Nature remains neutral with regard to jurisdictional claims in published maps and institutional affiliations. 